\title{
Studying boundary layer methane isotopy and vertical mixing processes at a rewetted peatland site using an unmanned aircraft system
}

\author{
Astrid Lampert ${ }^{1}$, Falk Pätzold ${ }^{1}$, Magnus O. Asmussen ${ }^{1}$, Lennart Lobitz $^{1}$, Thomas Krüger $^{1}$, Thomas Rausch $^{1}$, \\ Torsten Sachs ${ }^{1,2}$, Christian Wille ${ }^{2}$, Denis Sotomayor Zakharov ${ }^{3}$, Dominik Gaus ${ }^{3}$, Stephan Bansmer ${ }^{3}$, and \\ Ellen Damm ${ }^{4}$ \\ ${ }^{1}$ TU Braunschweig, Institute of Flight Guidance, Hermann-Blenk-Str. 27, 38108 Braunschweig, Germany \\ ${ }^{2}$ German Research Centre for Geosciences, Telegrafenberg, 14473 Potsdam, Germany \\ ${ }^{3}$ TU Braunschweig, Institute of Fluid Mechanics, Hermann-Blenk-Str. 37, 38108 Braunschweig, Germany \\ ${ }^{4}$ Alfred Wegener Institute, Helmholtz Centre for Polar and Marine Research, Am Handelshafen 12, \\ 27570 Bremerhaven, Germany
}

Correspondence: Astrid Lampert (astrid.lampert@tu-braunschweig.de)

Received: 21 March 2019 - Discussion started: 17 May 2019

Revised: 4 March 2020 - Accepted: 13 March 2020 - Published: 17 April 2020

\begin{abstract}
The combination of two well-established methods, of quadrocopter-borne air sampling and methane isotopic analyses, is applied to determine the source process of methane at different altitudes and to study mixing processes. A proof-of-concept study was performed to demonstrate the capabilities of quadrocopter air sampling for subsequently analysing the methane isotopic composition $\delta^{13} \mathrm{C}$ in the laboratory. The advantage of the system compared to classical sampling on the ground and at tall towers is the flexibility concerning sampling location, and in particular the flexible choice of sampling altitude, allowing the study of the layering and mixing of air masses with potentially different spatial origin of air masses and methane. Boundary layer mixing processes and the methane isotopic composition were studied at Polder Zarnekow in Mecklenburg-West Pomerania in the north-east of Germany, which has become a strong source of biogenically produced methane after rewetting the drained and degraded peatland. Methane fluxes are measured continuously at the site. They show high emissions from May to September, and a strong diurnal variability. For two case studies on 23 May and 5 September 2018, vertical profiles of temperature and humidity were recorded up to an altitude of 650 and $1000 \mathrm{~m}$, respectively, during the morning transition. Air samples were taken at different altitudes and analysed in the laboratory for methane isotopic composition. The
\end{abstract}

values showed a different isotopic composition in the vertical distribution during stable conditions in the morning (delta values of $-51.5 \%$ o below the temperature inversion at an altitude of $150 \mathrm{~m}$ on 23 May 2018 and at an altitude of $50 \mathrm{~m}$ on 5 September 2018, delta values of $-50.1 \%$ above). After the onset of turbulent mixing, the isotopic composition was the same throughout the vertical column with a mean delta value of $-49.9 \pm 0.45 \%$. The systematically more negative delta values occurred only as long as the nocturnal temperature inversion was present. During the September study, water samples were analysed as well for methane concentration and isotopic composition in order to provide a link between surface and atmosphere. The water samples reveal high variability on horizontal scales of a few tens of metres for this particular case. The airborne sampling system and consecutive analysis chain were shown to provide reliable and reproducible results for two samples obtained simultaneously. The method presents a powerful tool for distinguishing the source process of methane at different altitudes. The isotopic composition showed clearly depleted delta values directly above a biological methane source when vertical mixing was hampered by a temperature inversion, and different delta values above, where the air masses originate from a different footprint area. The vertical distribution of methane isotopic com- 
position can serve as tracer for mixing processes of methane within the atmospheric boundary layer.

\section{Introduction}

Methane's $\left(\mathrm{CH}_{4}\right)$ global warming potential is 32 times that of carbon dioxide $\left(\mathrm{CO}_{2}\right)$ on a century timescale (Etminan et al., 2016), and 72 times higher on a decadal timescale, producing a near-future, greater overall impact on the atmospheric radiative balance (Solomon et al., 2007). As a result, $\mathrm{CH}_{4}$ regulation has a far higher potential for nearterm climate change mitigation than $\mathrm{CO}_{2}$. Moreover, global warming feedbacks and rising anthropogenic emissions will likely increase $\mathrm{CH}_{4}$ emissions (Wunch et al., 2009). Yet, current knowledge of $\mathrm{CH}_{4}$ biogeochemical processes, transport and small-scale distribution remains inadequate. This is in part caused by the complex processes of production, transformation and transport and in part caused by the lack of sufficiently accurate assessments of the vertical distribution of methane and the temporal and spatial behaviour of highly variable anthropogenic and natural $\mathrm{CH}_{4}$ surface fluxes (Solomon et al., 2007). Global mean $\mathrm{CH}_{4}$ concentration increased until the early 1990s and then mostly stabilized for about a decade (Dlugokencky et al., 2003). Since 2007, growth has resumed (Dlugokencky et al., 2013), which is visible in the remote polar areas as well (Nisbet et al., 2016). The stabilization was proposed to have been a consequence of reduction in methane emissions from Siberian gas fields and other sources inside the Soviet Union after its collapse, changes in rice agriculture, and changes in microbial emissions (Dlugokencky et al., 2009). The recent increase has been proposed to be related to enhanced emissions from tropical wetlands associated with the extremely wet season in 2009 in the Amazon region (Dlugokencky et al., 2009; Chen et al., 2010).

Isotopic composition allows different source categories to be distinguished. Biologically produced methane has a typical $\delta^{13} \mathrm{C}$ ratio of $-70 \%$ to $-55 \%$ (France et al., 2016; Nisbet et al., 2016), methane from fossil fuels has a typical value of $-55 \%$ o to $-25 \%$ (Kirschke et al., 2013), and methane from fires has values of $-25 \%$ to $-13 \%$ o (Kirschke et al., 2013; Nisbet et al., 2016). Further, smaller differences in the isotopic composition are observed for different geographic regions. The background value of air in the free troposphere currently has a value of around $-47.4 \%$ at northern latitudes (Nisbet et al., 2016). The isotopic shift towards depleted (lower, more negative) $\delta^{13} \mathrm{C}$ values indicates an increasing share of biogenic origin (Nisbet et al., 2016).

The source process of methane and the importance of different natural sources is under discussion for various locations worldwide. Known sources in northern latitudes are permafrost areas (Sachs et al., 2010; France et al., 2016; Sasaki et al., 2016; Kohnert et al., 2018), the Arctic ocean
(Yu et al., 2015; Mau et al., 2017) and wetlands (Bellisario et al., 1999). Each source region has a unique isotopic composition, and mixing of different air masses results in a linear combination of the corresponding $\delta^{13} \mathrm{C}$ values (France et al., 2016). Field measurements of methane isotopic composition have been performed at the Cabauw tower at a sampling altitude of $20 \mathrm{~m}$, demonstrating the potential of isotopic analyses to determine contributions from isotopically different sources (Röckmann et al., 2016).

In the Arctic, inter-annual shifts in the sea ice drift patterns generate an inter-annually patchy methane excess in polar surface water and methane efflux (Damm et al., 2018). The source process of this enhanced methane concentration and the exchange processes between ocean, atmosphere and sea ice are subject to current investigation (Mau et al., 2017; Uhlig and Loose, 2017; Platt et al., 2018). The exchange of gas between air and sea strongly depends on the water stratification (Andersson et al., 2017). Further, isotopic fractionation towards depletion of $\delta^{13} \mathrm{C}$ in the range of a few to several per mille is observed at the water-air interface for diffusion processes (Happell et al., 1995).

The need to improve understanding of the heterogeneous methane sources and the transition from the surface into the atmosphere in the Arctic motivated the development of a flexible airborne sampling system, which provides information on atmospheric stability. In this context, unmanned aerial systems (UASs) fill an observational gap for methane mixing processes. They are able to sample small scales with a typical horizontal distance of $1 \mathrm{~km}$, if they are required to be operated in the line of sight, and they reach the top of the atmospheric boundary layer, with a maximum altitude of typically around $1 \mathrm{~km}$. UAS can be operated in remote areas, requiring less infrastructure in comparison with permanent measurement stations, and they can be used more flexibly than manned aircraft, enabling fast reactions to environmental events like changes of emissions through rain, drought, construction or fire.

The first applications of measuring the methane concentration with UAS have been demonstrated: the air sampling inlet integrated into multirotor systems is either directly connected to the ground-based methane analyser via a sampling line (Brosy et al., 2017), or the air is stored in a tubing, which is analysed after the flight with a cavity ring down spectrometer (Andersen et al., 2018). The limiting element for both techniques is the length and weight of the sampling line or tube, and sampling altitudes up to $50 \mathrm{~m}$ have been published (Brosy et al., 2017; Wolf et al., 2017; Andersen et al., 2018). An air sampling concept based on filling evacuated stainless steel containers by remotely opening a valve and subsequent chemical analyses of trace gases and first applications on multicopter systems have been shown (Chang et al., 2016, 2018). In situ methane analysers small enough to be integrated on a UAS have been presented (Gurlit et al., 2005; Miftah El Khair et al., 2017; Graf et al., 2018), and the first scientific articles showing field measurements of 
in situ multicopter-borne methane concentrations up to an altitude of $600 \mathrm{~m}$ have been published (Golston et al., 2017). The method of air sampling and methane isotopic analyses has been applied to (manned) airborne measurements with high payload capacity in the lower troposphere, e.g. above Siberian peatlands to distinguish emissions from fossil and biogenic emissions (Umezawa et al., 2012), up to balloonborne observations to study sink mechanisms of methane in the stratosphere (Sugawara et al., 1997).

The goal of the study is a proof of concept for the experimental set-up of the quadrocopter-borne sampling system, and subsequent laboratory analyses, to identify vertical layers of different isotopic composition.

In order to test the system's capabilities of providing reliable vertical profiles of the isotopic composition, measurements were performed at a rewetted peatland site, Polder Zarnekow (Zerbe et al., 2013), which is known as a source of biologically produced methane (Franz et al., 2016). In the absence of turbulent mixing, which typically happens during nighttime, local emissions of the wetlands produce a depleted delta value compared to the atmospheric background above the temperature inversion. During the morning transition, when the stable stratification is gradually replaced by a convectively mixed atmospheric boundary layer, the isotopic composition should adjust to a near-constant delta value throughout the profile within the uncertainties of laboratory air sample isotopic analyses. To show the small-scale horizontal inhomogeneity at the study site, the methane concentration of water samples from locations within a radius of $100 \mathrm{~m}$ was analysed.

\section{Methods}

In the following, the quadrocopter ALICE (airborne tool for methane isotopic composition and polar meteorological experiments) as the carrier system, the payload consisting of the air sampling subsystem and the meteorological sensors, and data acquisition are described. Further, the laboratory air analysis procedures and the measurement site for system tests are introduced. For evaluating the whole measurement chain, a local source of methane of particular isotopic composition and atmospheric conditions that first inhibit and then enforce vertical mixing processes (morning transition) were required. These conditions were met at Polder Zarnekow on 23 May 2018. For confirming the results, the same measurement strategy was applied to the same site on 5 September 2018.

\subsection{Quadrocopter ALICE and instrumentation}

The quadrocopter ALICE was designed as a platform to carry meteorological sensors and 12 glass bottles for air sampling (Fig. 1). The construction of the quadrocopter was calculated for the specific tasks and the payload described in the fol- lowing. Therefore, all relevant load cases that were expected during the flight were applied in analytical and numerical models to optimize the structure of the quadrocopter. Modern manufacturing methods like selective laser sintering and laser cutting where used to build the structure as lightweight as possible but as stable as necessary. ALICE has dimensions of $1.82 \mathrm{~m} \times 1.82 \mathrm{~m} \times 0.78 \mathrm{~m}$ including the scientific payload. The arms are quickly removable (rotating lock) for convenient storage and transport. At a tare weight of $6.3 \mathrm{~kg}$, ALICE's maximum take-off weight is $25 \mathrm{~kg}$. For the operations presented here, the total weight was $19 \mathrm{~kg}$, which is composed of the quadrocopter system itself $(6.3 \mathrm{~kg})$, lithium polymer (LiPo) batteries with a total capacity of $21 \mathrm{Ah}$ and a nominal voltage of $44.4 \mathrm{~V}$ for rotor power supply (4.9 kg), and a payload including sensors, glass bottles, data acquisition, power supply for payload and a safety parachute of $12 \mathrm{~m}^{2}(7.8 \mathrm{~kg})$. The payload is placed in the centre of the system on a platform with dimensions of $370 \mathrm{~mm} \times 370 \mathrm{~mm}$. The temperature and humidity sensors are located in a housing to shield against radiation and protect against impact of dust at the edge of the platform. An electronics box contains the central data acquisition.

The quadrocopter is constructed with a thrust-to-weight ratio of $2: 1$. Each propeller has a diameter of $330 \mathrm{~mm}$. The system was designed for wind speeds up to $35 \mathrm{~km} \mathrm{~h}^{-1}$ during take-off and landing, and up to $70 \mathrm{~km} \mathrm{~h}^{-1}$ during free flight. At a wind speed of $60 \mathrm{~km} \mathrm{~h}^{-1}$, a climb rate of the current system of $8 \mathrm{~m} \mathrm{~s}^{-1}$ was still possible. ALICE has been designed to reach altitudes up to $1 \mathrm{~km}$. It is electrically powered with four motors (U11 KV120 from T-Motor, China).

As the system was intended for operations in the polar regions, the design point of the system is $-30^{\circ} \mathrm{C}$. All parts have been tested extensively in a climate chamber down to $-30{ }^{\circ} \mathrm{C}$, taking into account vibrations of the carrier, which were simulated with a shaker after in-flight measurements. The pre-heated batteries are insulated passively, and the temperatures of the batteries and the internal avionics are monitored.

Air temperature is recorded with various temperature sensors of different behaviour. Fast fine-wire temperature sensors, manufactured at the Institute of Flight Guidance (Bärfuss et al., 2018), have the advantage of a high temporal resolution up to $100 \mathrm{~Hz}$. Further, standard long-term stable sensors were used (Pt1000 "Humicap" HMP110, Vaisala, Finland; digital sensor TSYS01, Measurement Specialities, US). Relative humidity is measured with two different sensors, the Humicap HMP110 (Vaisala, Finland) and the Rapid P14 (Innovative Sensor Technology, Switzerland). Absolute pressure is recorded with AMSYS 5812-0150-B sensors, AMSYS, Germany. Two pyranometers, ML-01 of EKO Instruments, Japan, with nadir and zenith viewing geometry are integrated, which allow cloudiness and surface properties to be estimated at a sampling rate of $100 \mathrm{~Hz}$. Further, a surface temperature sensor Melexis MLX90614, Belgium, is mounted onto the airframe and fixed at the bottom of the 


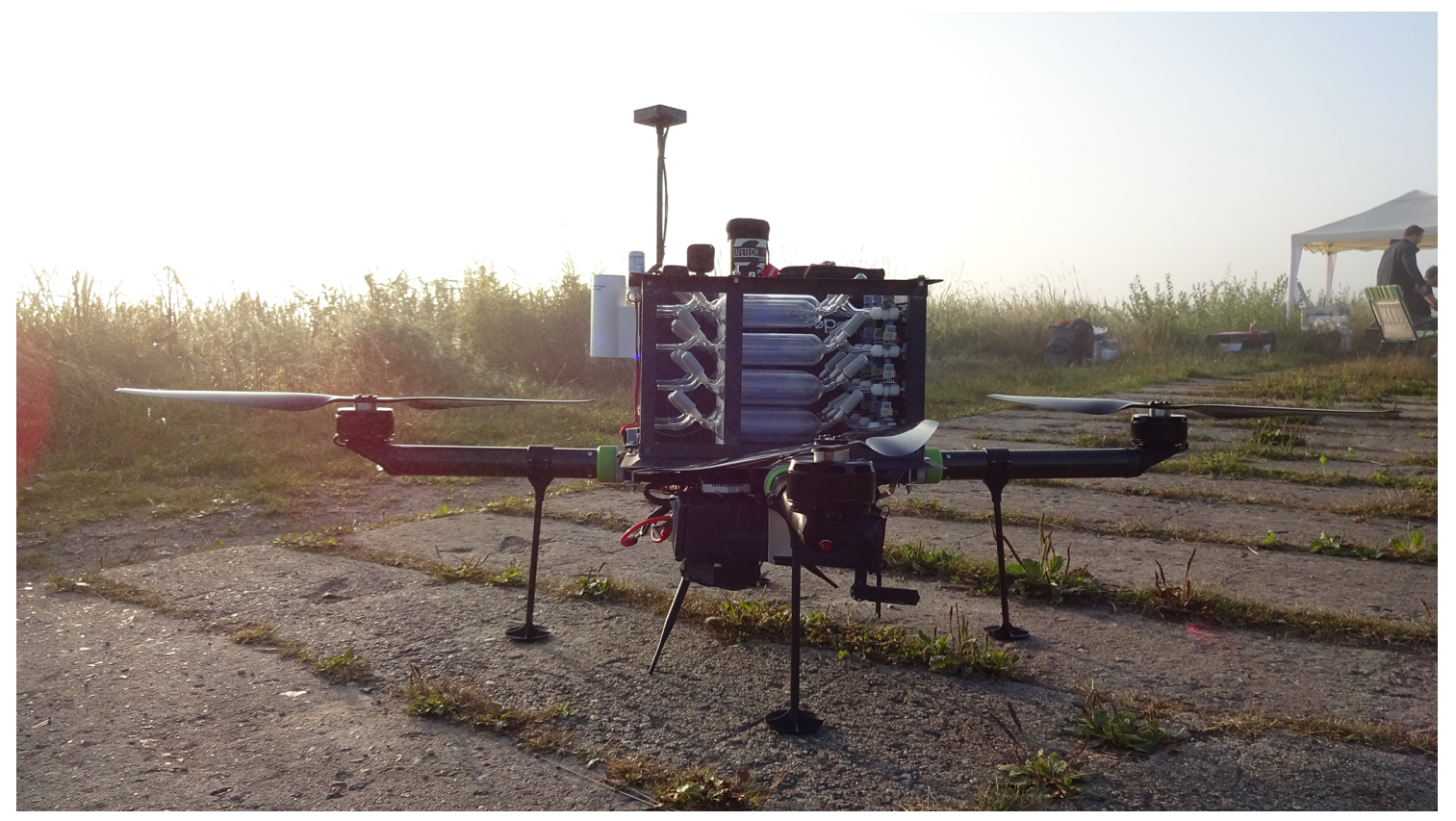

Figure 1. The quadrocopter ALICE before take-off in Zarnekow on 5 September 2018.

UAS. A global navigation satellite system (GNSS) receiver and an inertial measurement unit (IMU) ADIS16488 (Analog Devices, US) are integrated. Data are recorded at a sampling frequency of $100 \mathrm{~Hz}$.

The air sampling system consists of 12 glass flasks (sample containers) of $100 \mathrm{~mL}$ volume, which are evacuated before take-off. Their arrangement with respect to the copter can be seen in Fig. 1. The distance from the tip of the closest rotor blades to the inlet is approximately $7 \mathrm{~cm}$. The glass flasks are equipped with two manual valves, one on each side, and additionally one electromagnetic valve, which is applied only during the flight (Fig. 2). Directly before the mission, each glass flask is linked with a vacuum pump RE5 from Vacuubrand, Germany. One valve is left open, and an electromagnetic valve is connected, which is normally closed. Then the flask is evacuated, and the pressure is controlled by a pressure sensor integrated in the electromagnetic valve. The flasks are opened during the flight with magnet valves, which are triggered either manually by remote control or automatically at altitudes predefined by the operator. After triggering, ambient pressure is reached within approximately $1.3 \mathrm{~s}$. The pressure sensors integrated in the valves are used to monitor how airtight they are. The most delicate components are the manual plastic valves, used to close the glass flasks for transport, which are designed to be airtight when closed, but not when open. They had to be treated individually and controlled to make sure that no leakage occurred during the mission. For quality control and redundance, two glass flasks were filled simultaneously, resulting in six possible sampling altitudes during one flight.
The onboard data are downlinked to a ground station and displayed to the operator. Depending on the atmospheric structure, the operator decides on the altitude of taking samples during the descent, e.g. above/below the temperature inversion, or within altitudes of enhanced humidity, as required for the scientific question. The whole mission can be flown automatically by a Pixhawk autopilot. It is supervised by a safety pilot and a scientific operator who is controlling the system and performance as well as the measurements. Two small cameras, one pointing downwards (GoPro HERO5 Black, 12 megapixels), one looking to the side (GoPro HERO Session Actionkamera, 8 megapixels), were integrated. The captured video of the downward-pointing camera was transmitted to the operator with 720-pixel resolution and $60 \mathrm{~Hz}$. There are different telemetry connections: a $2.4 \mathrm{GHz}$ link is used for the remote control. A $868 \mathrm{MHz}$ connection serves to send commands to the autopilot, and an $868 \mathrm{MHz}$ link is used for activating the safety parachute trigger. Further, a $5.8 \mathrm{GHz}$ video link is established. Scientific data are transmitted via a $433 \mathrm{MHz}$ connection.

\subsection{Quadrocopter flow simulations and impact on sampling}

In order to quantify the effect of the vertical flow induced by the quadrocopter, numerical simulations were performed with the software ANSYS CFX. The simulations were transient in nature using a Reynolds-averaged Navier-Stokes (RANS) approach with the shear-stress transport (SST) turbulence model (Menter, 1994). A simplified model of the propeller blade was used, with a multidomain approach: The 


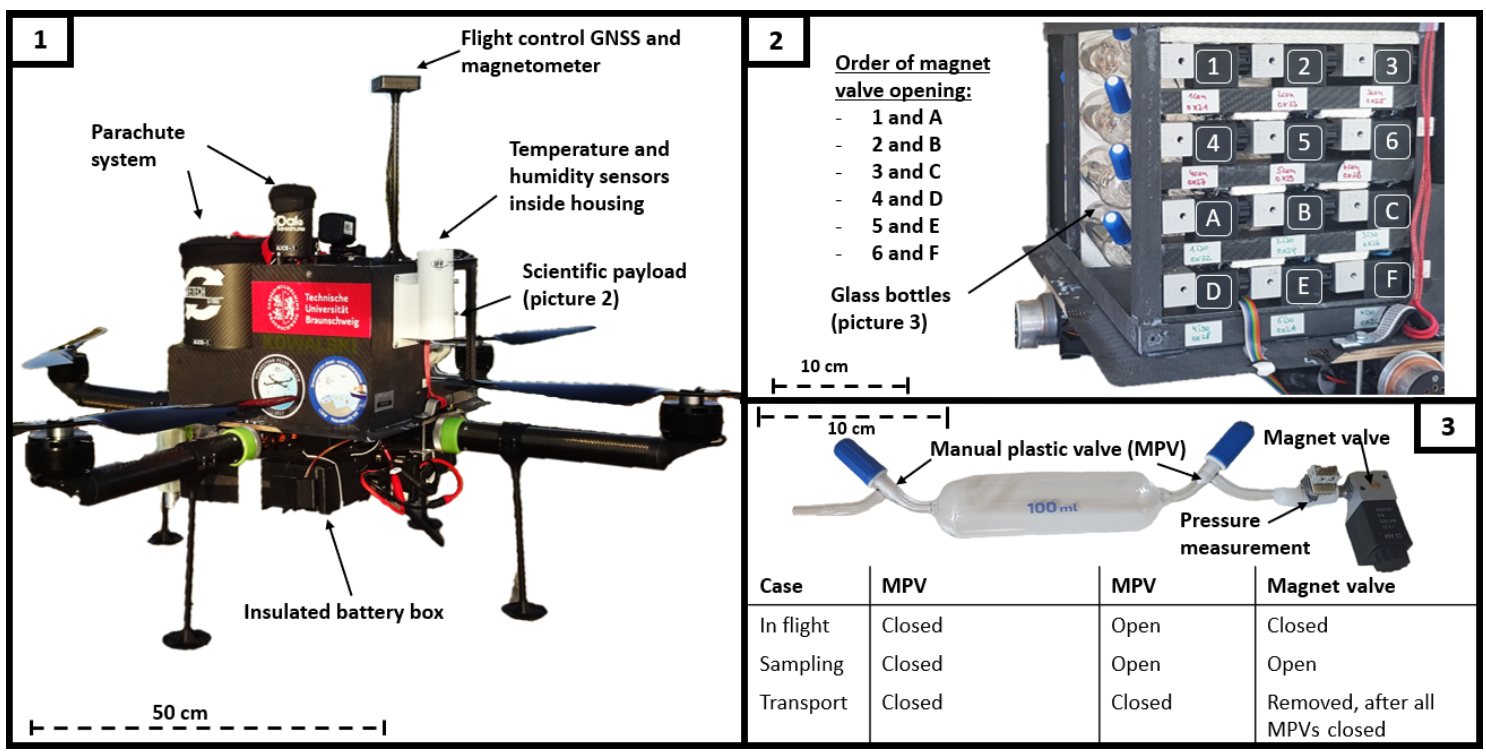

Figure 2. ALICE vital components. (1) Overall view of the system. (2) Gas sampling payload consisting of 12 evacuated glass flasks which can be filled by opening an electromagnetic valve during the flight. The positions of the two samples taken simultaneously are indicated. (3) Principle of air sampling with manual and electromagnetic valves, showing the configurations of the valves during flight, sampling and transport.

blade is enclosed in a rotating domain, surrounded by a static domain. Simulations were performed for hover with a propeller rotation speed of $3167 \mathrm{~min}^{-1}$, for vertical climb at a speed of $6.5 \mathrm{~m} \mathrm{~s}^{-1}$ with a rotation speed of $3913 \mathrm{~min}^{-1}$ and of vertical descent at a speed of $-2.5 \mathrm{~m} \mathrm{~s}^{-1}$ with a rotation speed of $2880 \mathrm{~min}^{-1}$. An ambient temperature of $0^{\circ} \mathrm{C}$ and pressure of $1023 \mathrm{hPa}$ were considered. Contours of relative vertical velocity show a core region of positive relative velocity directly below the centre of the blade, and a negative relative velocity up to $19 \mathrm{~m} \mathrm{~s}^{-1}$ below the blade for a distance exceeding $0.75 \mathrm{~m}$ (Fig. 3). Additionally, zones of recirculation can be seen around the tips of the propeller, especially for the descent case. The air sampling system is contained in the middle of the copter and is less affected by artificial turbulence than the areas below the rotor blades.

Assuming that in the worst case the sampling takes place within the downwash of the rotor blades of not more than $-19 \mathrm{~m} \mathrm{~s}^{-1}$, the sampling time of $1.3 \mathrm{~s}$ duration results in a vertical resolution of around $25 \mathrm{~m}$. Sampling during descent with a speed of $-2.5 \mathrm{~m} \mathrm{~s}^{-1}$ adds an uncertainty in the altitude of $5 \mathrm{~m}$. Altogether, the sampling is influenced by air in a height interval of $30 \mathrm{~m}$. This is sufficient for the sampling intervals of around $100 \mathrm{~m}$, and for determining that the sampling was done below or above the temperature inversion.

A more realistic estimate of the altitude interval uncertainty assumes the vertical velocities directly next to the rotor blade tips (see Fig. 1): the highest induced speed in close proximity of the tips of the rotor blades during descent is $-8 \mathrm{~m} \mathrm{~s}^{-1}$ (Fig. 3). This results in an altitude interval of around $10 \mathrm{~m}$ caused by the flow field plus an altitude interval of $5 \mathrm{~m}$ due to the vertical descent speed. Therefore, a realistic estimate of the altitude influencing the sampled air is $15 \mathrm{~m}$.

\subsection{Laboratory isotopic analyses}

Following the quadrocopter mission, the sample containers (SCs) were transported to the laboratory at the Alfred Wegener Institute in Bremerhaven, Germany, for analysis of the isotopic composition. The $\delta^{13} \mathrm{C}$ value of the air samples was analysed using a Delta plus XP mass spectrometer combined with a combustion oven, a gas pressure interface and a preconcentration device (PreCon) (ThermoFinnigan, Bremen, Germany). All valves and traps are automatically operated by the mass spectrometer software. Each SC was installed onto the PreCon and the connections were flushed with helium before the SC was opened. The air sample was first carried by helium carrier gas through a chemical trap and then trapped in a cool box filled with liquid nitrogen $\left(-196^{\circ} \mathrm{C}\right)$ to remove $\mathrm{CO}_{2}, \mathrm{CO}$ and $\mathrm{H}_{2} \mathrm{O}$. Afterwards the $\mathrm{CO}_{2}$-free air was carried by helium carrier gas to the combustion oven $\left(1000^{\circ} \mathrm{C}\right)$ for methane conversion into $\mathrm{CO}_{2}$ which then was purged into a second cool box filled with liquid nitrogen and trapped therein. When the combustion is finished, the gas stream is purged and trapped in a third cool box filled with liquid nitrogen to pre-concentrate the sample and carried by helium carrier gas into the isotope ratio mass spectrometer. Methane stable carbon isotope data are given in $\delta$ notation (in \%o) rel- 


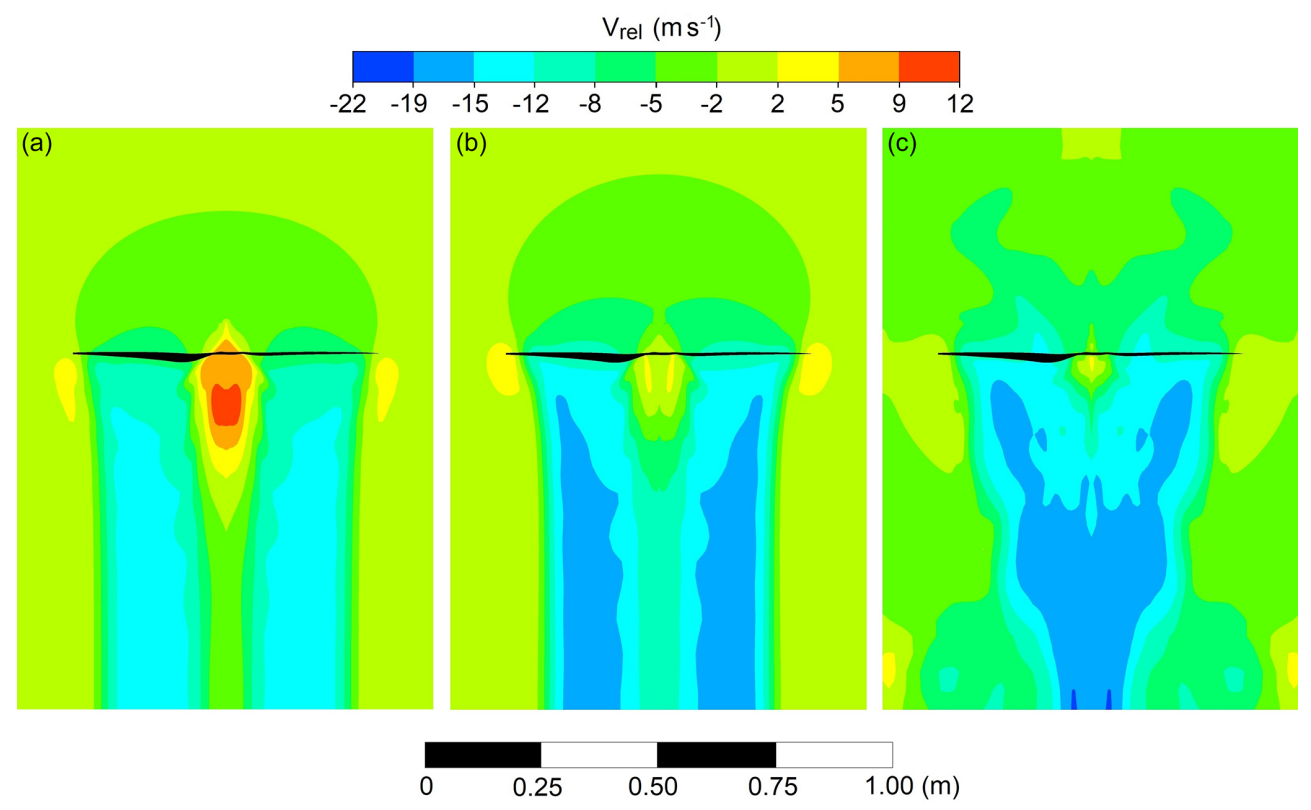

Figure 3. Simulation of the relative vertical flow velocity $\left(V_{\text {rel }}\right)$ induced by a propeller blade during hover (a), vertical climb at a speed of $6.5 \mathrm{~m} \mathrm{~s}^{-1}$ (b) and descent at a speed of $-2.5 \mathrm{~m} \mathrm{~s}^{-1}$ (c). Downward-pointing velocities have a negative sign.

ative to the Pee Dee Belemnite (PDB) standard:

$\delta^{13} \mathrm{C} \% o=\left(\frac{{ }^{13} \mathrm{C} \text { sample }}{{ }^{13} \mathrm{C}}-1\right) \cdot 1000$.

Precision, determined as the maximum difference of delta values during repeated analysis of ambient Bremerhaven air samples taken simultaneously and analysed consecutively many times per year, is better than $0.5 \%$. Further applications of the system have been described in Mau et al. (2013), Damm et al. (2015), Verdugo et al. (2016) and Fenwick et al. (2017).

\subsection{Study site}

The shallow Polder Zarnekow with a water depth of less than $1 \mathrm{~m}$ belongs to a large area of rewetted peatlands in the Peene River valley in north-eastern Germany $\left(53^{\circ} 52.5^{\prime} \mathrm{N}\right.$, $12^{\circ} 53.3^{\prime} \mathrm{E}$, less than $0.5 \mathrm{ma}$ a.s.1). It formed after the dikes were opened in 2004-2005 in order to restore the peatlands, taking up $\mathrm{CO}_{2}$ to reduce greenhouse gases. The total rewetted area is 421 ha in size (Gelbrecht et al., 2008). The site is a Fluxnet site (DE-Zrk) and is part of the Northeast German Lowland Observatory of the Terrestrial Environmental Observatories Network, TERENO (Heinrich et al., 2018).

It is equipped with state-of-the-art eddy covariance (EC) instrumentation recording the wind vector; temperature; and the concentration of water vapour, $\mathrm{CH}_{4}$ and $\mathrm{CO}_{2}$ at a frequency of $20 \mathrm{~Hz}$. The measurement height above the water surface is around $2.6 \mathrm{~m}$, depending on the water level. Water vapour and $\mathrm{CO}_{2}$ are measured with an LI-7200 sensor from
LI-COR, US. Methane is measured with a LI-COR sensor LI-7700. Further, a Los Gatos Fast Greenhouse Gas Analyser (FGGA, US) records the concentration of the three greenhouse gases at a frequency of $20 \mathrm{~Hz}$. Four automatic measurement chambers are installed along a transect between the EC system and the shore of the lake for spatially resolved $\mathrm{CO}_{2}$ and $\mathrm{CH}_{4}$ flux investigations (Hoffmann et al., 2017).

The restoration of the peatland area towards a net sink of the greenhouse gas $\mathrm{CO}_{2}$ is a process lasting from several years to decades. Initially, the restoration is accompanied by a strong increase in $\mathrm{CH}_{4}$ emissions, which depend on vegetation and the water level (Couwenberg et al., 2011; Zak et al., 2015). The shallow eutrophic lake in particular acts as a strong source of $\mathrm{CH}_{4}$ (Franz et al., 2016). Maximum methane emissions are typically observed in summer (Franz et al., 2016). In the diurnal cycle, the maximum $\mathrm{CH}_{4}$ emissions were recorded during nighttime (Franz et al., 2016). This is in agreement with stronger convective mixing of the lake induced thermally from May to October (Franz et al., 2016), which leads to diffusive $\mathrm{CH}_{4}$ emissions (Hoffmann et al., 2017). Time series of methane fluxes of the 3-year period 2016 to 2018 reveal a high variability over the entire period and within time periods of a few days, with noticeable fluxes during the growing season between May and September (not shown).

\subsection{Water sampling}

For identifying the reason for small-scale inhomogeneities of the atmospheric methane isotopic composition, the methane source located within the surface water was sampled at differ- 
ent locations on 5 September 2018. Six water samples were taken with Kemmerer glass bottles of $50 \mathrm{~mL}$ at the locations Z-1 to Z-6 indicated in Fig. 4. After filling and locking with screw cap, the water samples were stored and transported light-proof in a cool box. They were analysed in the laboratory for methane concentration and isotopic composition at the Alfred Wegener Institute in Bremerhaven on 6 and 7 September 2018, thus directly after the sampling.

\subsection{Flight strategy}

The aerial measurement strategy consists of an automatic climb flight up to $1 \mathrm{~km}$ altitude and down again with realtime data transmission of selected parameters at $1 \mathrm{~Hz}$. For the missions presented here, a permission from the nature protection agency and coordination with the German Civil Aviation Agency (DFS, Deutsche Flugsicherung) were required. Flights were permitted between sunrise and sunset. As it takes some hours until the nocturnal temperature inversion is replaced by a well-mixed boundary layer with increasing solar radiation, it was possible to take the air samples during the transition from nocturnal stable boundary layer to the convectively mixed boundary layer.

On 23 May 2018, three consecutive measurement flights of around $10-11$ min duration were performed over a time period of $3 \mathrm{~h}$ in the morning, with take-off times of 06:04, 07:30 and 08:29 UTC, corresponding to a local time between 08:04 and 10:29LT. Sunrise was at 04:55 LT.

Each flight consisted of manual take-off and climb up to around $50 \mathrm{~m}$ altitude, then handing over the system to the autopilot. The flight pattern followed three waypoints at $50 \mathrm{~m}$ altitude leading to a position directly above the open water fraction of the polder. There, a vertical ascent with a mean vertical speed of $5 \mathrm{~m} \mathrm{~s}^{-1}$ up to a height of $650 \mathrm{~m}$ a.g.l. and subsequent descent with a vertical speed of $-2 \mathrm{~m} \mathrm{~s}^{-1}$ took place. For this feasibility study, air samples were taken during descent at the approximate altitudes of 600, 400, 300, 200,100 and $10 \mathrm{~m}$. Then the quadrocopter flew to a waypoint close to the landing point and was landed manually. During ascent, the temperature profiles were studied, as a base to plan sampling altitudes for the descent. The air samples were analysed in the laboratory for methane isotopic composition at the Alfred Wegener Institute in Bremerhaven on 11, 12 and 13 June 2018, thus 3 weeks after the sampling.

On 5 September 2018, five consecutive measurement flights of around 12-13 min duration were performed over a time period of $5 \mathrm{~h}$ in the morning, with take-off times of 06:04, 07:15, 09:12, 10:05 and 10:57 UTC, corresponding to a local time between 08:04 and 12:57 LT. Sunrise was at 06:23 LT. The same flight strategy as described above was applied. The ascents reached an altitude of $1000 \mathrm{~m}$, but the sampling altitudes remained the same. The vertical ascents were done with a mean vertical speed of $6.5 \mathrm{~m} \mathrm{~s}^{-1}$ and the descents with a vertical speed of $-2.5 \mathrm{~m} \mathrm{~s}^{-1}$.
The quadrocopter data are available at the data centre PANGAEA (Pätzold et al., 2019).

\section{Results}

\subsection{Synoptic conditions and meteorological observations}

On 23 May 2018, the synoptic situation was characterized by a pronounced high-pressure system above Scandinavia and the Baltic Sea, leading to conditions of low wind speed below $5 \mathrm{~m} \mathrm{~s}^{-1}$, north-easterly wind directions and a cloudless sky, as indicated from the smooth behaviour of global radiation (Fig. 5).

On 5 September 2018, the synoptic situation was determined by two strong high-pressure systems located above the Atlantic Ocean and above northern Russia, and a lowpressure system above southern Europe. This resulted in low wind speed below $4 \mathrm{~m} \mathrm{~s}^{-1}$ in the north-easterly direction at the observation site, similar to the conditions on 23 May 2018. As the eddy flux tower is located at the north-east of the polder, flux footprints are influenced by areas outside of the polder area (see Figs. 11 and 4). As the profile measurements were performed directly above the polder, the sampled air has a different footprint. The locations of the water samples are all outside the footprint area of the EC tower.

In the morning, until 05:30 UTC, around $30 \mathrm{~min}$ before the first flight, fog was observed, which was denser towards the east. Starting around 09:00 UTC, before flight 3, shallow convective cumulus clouds were present. This is also evident in the high variability of the global radiation (Fig. 6).

On 23 May 2018, the near-surface temperature increased from around $13-14{ }^{\circ} \mathrm{C}$ at $06: 00 \mathrm{UTC}$ to around $17^{\circ} \mathrm{C}$ at 08:30 UTC (Fig. 7). The profiles of potential temperature show a strongly stable stratification in the morning, with an increase in potential temperature of around $2{ }^{\circ} \mathrm{C}(06: 04$ UTC $)$ from the surface to $250 \mathrm{~m}$. The top of the nocturnal temperature inversion was located at around 150 to $250 \mathrm{~m}$ altitude. At this altitude range, the water vapour mixing ratio decreased as well from around $7 \mathrm{~g} \mathrm{~kg}^{-1}$ in the boundary layer close to the surface to around $5 \mathrm{~g} \mathrm{~kg}^{-1}$ above. After 07:30 UTC, the atmosphere was less stably stratified. The water vapour mixing ratio was enhanced in the lowermost $150 \mathrm{~m}$ at 06:04 UTC. Above and later, the water vapour mixing ratio was almost constant with height.

On 5 September 2018 during the first flight, the profiles show a mixed layer up to $50 \mathrm{~m}$ altitude and a stable stratification above (Fig. 8). The water vapour mixing ratio was lower in the mixed layer $\left(11 \mathrm{~g} \mathrm{~kg}^{-1}\right)$ and increased above up to $14 \mathrm{~g} \mathrm{~kg}^{-1}$. For the following four flights, the nearsurface temperature increased, and the potential temperature increased only slightly with altitude. The water vapour mixing ratio decreased with time throughout the whole profile. 


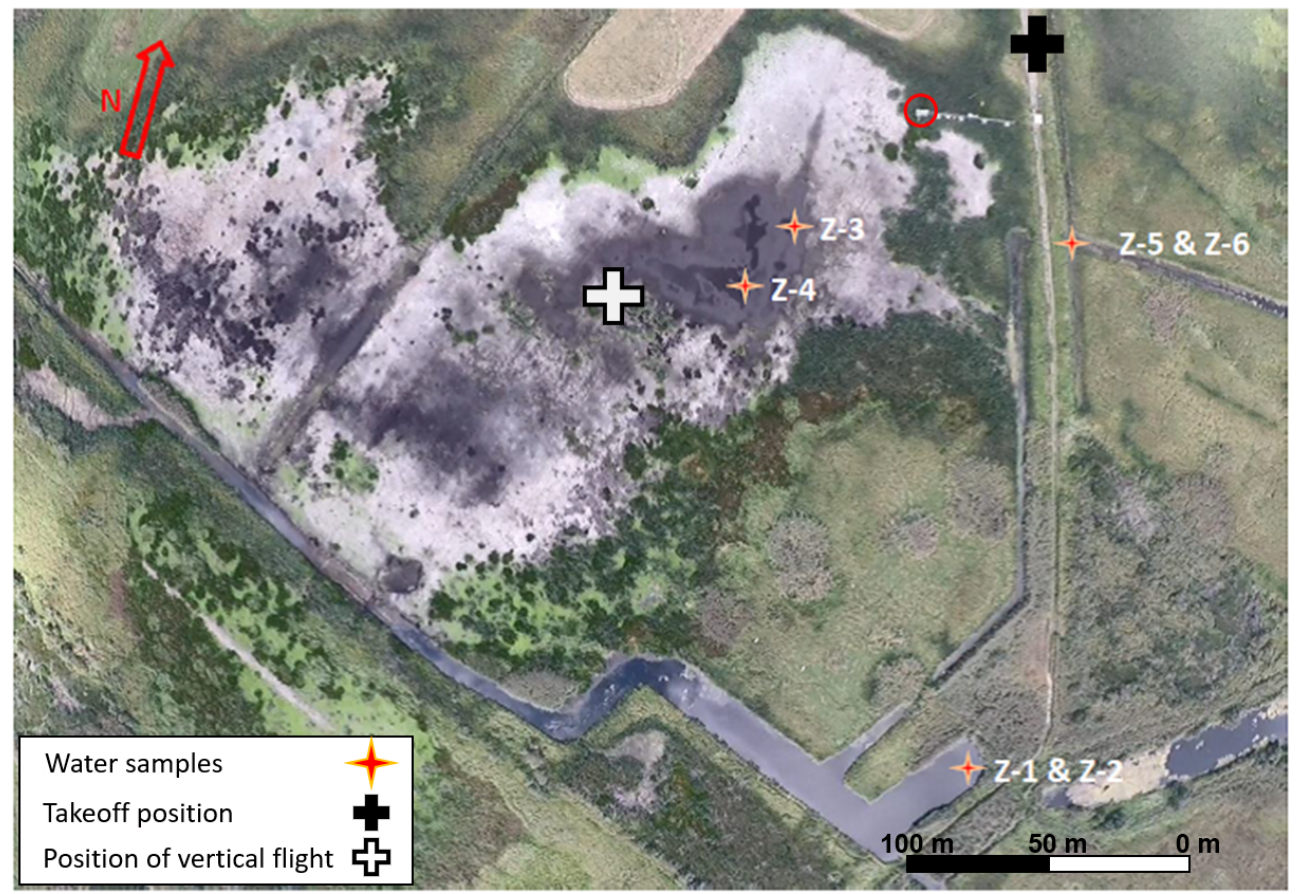

Figure 4. Aerial picture of Polder Zarnekow obtained with the quadrocopter ALICE on 5 September 2018. Almost the whole polder dried out after the extremely warm and dry summer 2018. The sites where water samples were taken are indicated with Z1 to Z6. The location of the EC station is indicated with a red circle.

\subsection{Observations of methane concentrations and isotopic composition}

For both observation days, the methane concentration recorded at the eddy covariance tower at $2.6 \mathrm{~m}$ altitude above the surface shows a high variability during the night and the morning, and a relatively constant concentration during the day. During the time period of the first flight on 23 May 2018, the methane concentration was still slightly enhanced compared to the background value during the day (Fig. 5). The first flight on 5 September 2018 took place during the high fluctuations of the $\mathrm{CH}_{4}$ concentration (Fig. 6).

The isotopic composition of the air samples was different during the first flight of each day at the altitudes located within the stable stratification. On 23 May 2018, the delta value was depleted at $10 \mathrm{~m}$ and $100 \mathrm{~m}$ altitude with a value of $-51.5 \%$ (see Fig. 9). Above, the mean delta was $-50.1 \%$, almost the same as during the next flights throughout the profile, with an average value of $-49.9 \%$. On 5 September 2018, the same systematic behaviour was observed: During the first flight, the delta value was depleted at an altitude of $10 \mathrm{~m}$, in agreement with a temperature inversion above an altitude of $50 \mathrm{~m}$. Above, the delta value of $-49.9 \%$ was the same as during all other flights throughout the profile (Fig. 10).

Aerial pictures obtained during the measurement flights for the two case studies show the difference in water level: on 23 May 2018, the lake was filled with water (Fig. 11).
On 5 September 2018, almost the whole lake had fallen dry, with only few wet areas remaining and the sediment still saturated with water (Fig. 4). The depth was in the range of few centimetres.

The water samples taken on 5 September 2018 within a radius of $100 \mathrm{~m}$ revealed highly different $\mathrm{CH}_{4}$ concentrations (see Table 1). The highest $\mathrm{CH}_{4}$ concentration of around $4770 \mathrm{ppm}$ was measured from the water sample Z-4 in one of the small remaining water areas with a depth less than $5 \mathrm{~cm}$ within the former polder. Directly next to this, the water sample Z-3 taken at a depth of 5-10 cm had a methane concentration of $2310 \mathrm{ppm}$ (see Fig. 4 for exact locations). The water sample Z-4 contained more suspended sediment load than sample Z-3. The sample sites are located within small remaining water areas, which are not connected.

\section{Discussion}

\subsection{Plausibility of the observed isotopic composition}

Methane flux data indicate that the observation site was a source of methane during both measurement days but had much higher emissions on 23 May 2018 (not shown). During the first flights in the early morning, under stable stratification, an enhanced methane concentration representing local emissions close to the observation site can be expected (Röckmann et al., 2016), as observed by Andersen et al. 


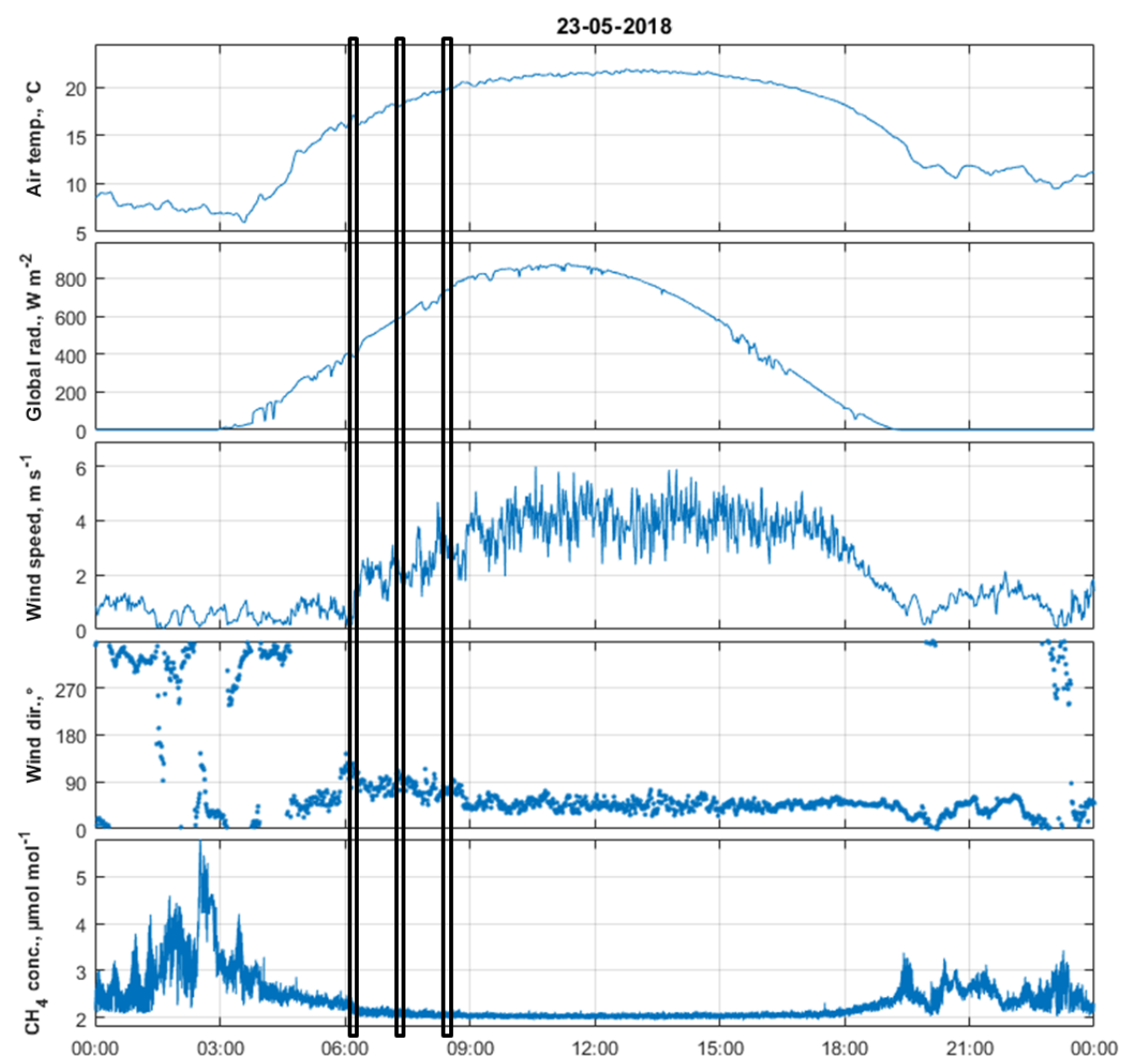

Figure 5. Diurnal course of the main meteorological parameters air temperature, global radiation, wind speed, wind direction and methane concentration (closed-path Los Gatos sensor) recorded at the meteorological mast at Zarnekow on 23 May 2018. The times of the quadrocopter air sampling are indicated by vertical boxes.

Table 1. Water samples on 5 September 2018: location and water depth of sampling, colour, concentration and delta value.

\begin{tabular}{|c|c|c|c|c|c|}
\hline Number & location & Water depth & Colour & Conc. (ppm) & Delta value $(\% o)$ \\
\hline $\mathrm{Z}-1$ & Peene River influx, surface water, $2 \mathrm{~m}$ from shore & $5-10 \mathrm{~cm}$ & middle yellow & 0.339 & -30.5 \\
\hline $\mathrm{Z}-2$ & Peene River influx, deep water, $2 \mathrm{~m}$ from shore & $40-50 \mathrm{~cm}$ & middle yellow & 0.246 & -30.1 \\
\hline Z-3 & Polder Zarnekow, surface water, pond, $30 \mathrm{~cm}$ from edge & less than $5 \mathrm{~cm}$ & strong yellow & 2312.7 & -42.8 \\
\hline $\mathrm{Z}-4$ & Polder Zarnekow, surface water, pond & $5-10 \mathrm{~cm}$ & strong yellow & 4765.2 & -48.2 \\
\hline Z-5 & Trench in the east, $1 \mathrm{~m}$ from shore, between plants & $5-10 \mathrm{~cm}$ & light yellow & 111.38 & -5.1 \\
\hline Z-6 & Trench in the east, near shore & $5-10 \mathrm{~cm}$ & light yellow & 2397.9 & -49.2 \\
\hline
\end{tabular}

(2018) above wetlands. A stable stratification was present at the beginning on both measurement days with the UAS. An enhanced methane concentration and high variability was observed until around 06:30 UTC on 23 May 2018 (Fig. 5), and even higher concentrations and stronger fluctuations were observed until 06:45 UTC on 5 September 2018 (Fig. 6). Under stable atmospheric conditions and low wind speed smaller than $2 \mathrm{~m} \mathrm{~s}^{-1}$ during the night and in the early morning hours, the near-surface methane concentration is enhanced, as vertical mixing is hampered, in agreement with Emeis (2008) and Brosy et al. (2017). This can be seen in the time series of the methane concentrations for both days as well (Figs. 5 and 6). During the flights, the methane concentration was already smaller again, which can be explained by vertical mixing up to the temperature inversion. This mixing also influences the isotopic composition. With a local methane source, the near-surface methane concentration above agricultural land therefore increases during stable atmospheric conditions (Wolf et al., 2017), as these prevent mixing with the free troposphere. However, a high local horizontal inhomogeneity in methane concentrations resulting from mixed-use areas has been reported, an effect which is visible in the lowermost $10 \mathrm{~m}$ above the surface but smeared out above due to an increase in horizontal wind speed (Wolf 


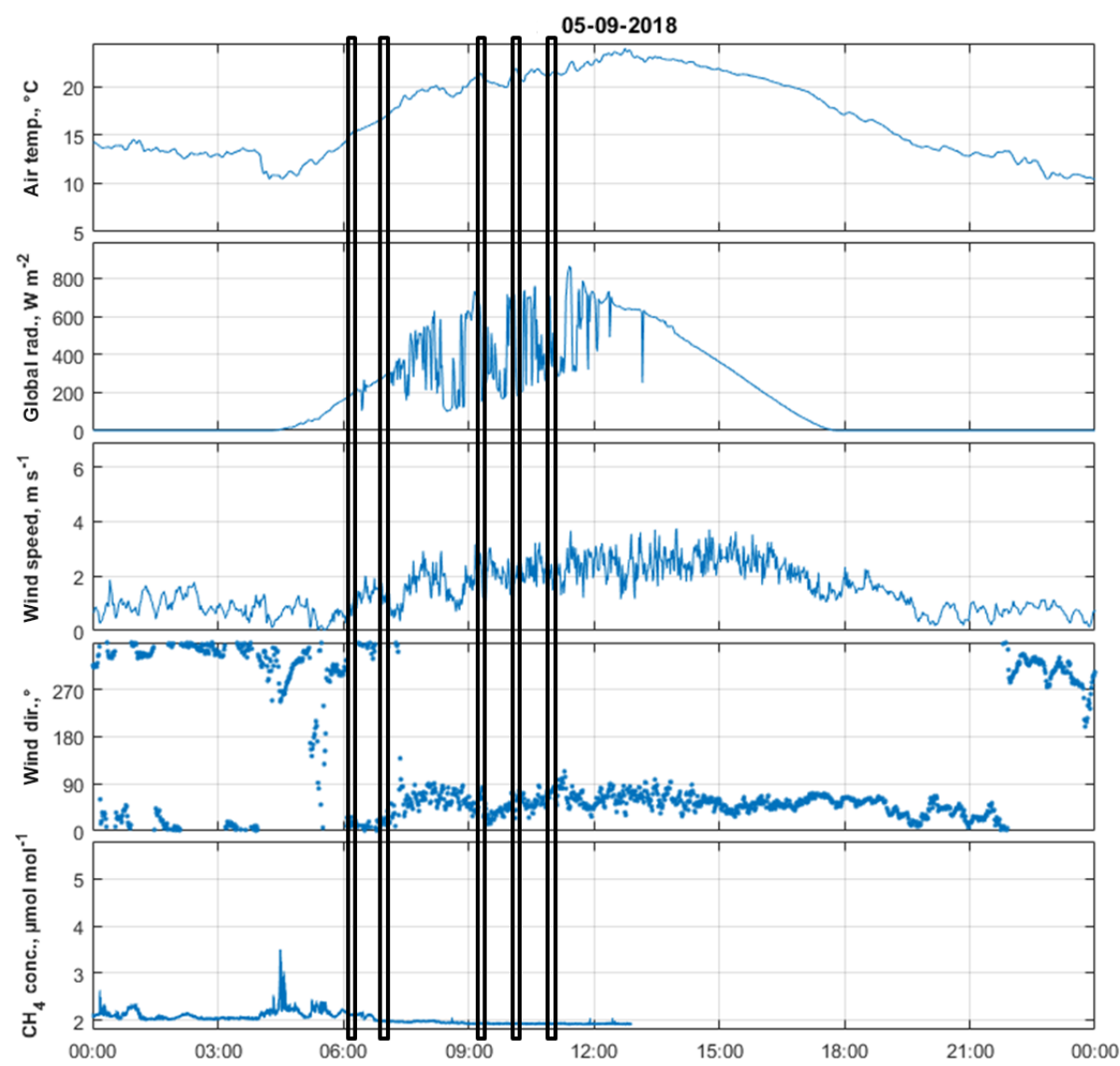

Figure 6. Diurnal course of the main meteorological parameters air temperature, global radiation, wind speed, wind direction and methane concentration (closed-path Los Gatos sensor) recorded at the meteorological mast at Zarnekow on 5 September 2018. The times of the quadrocopter air sampling are indicated by vertical boxes.
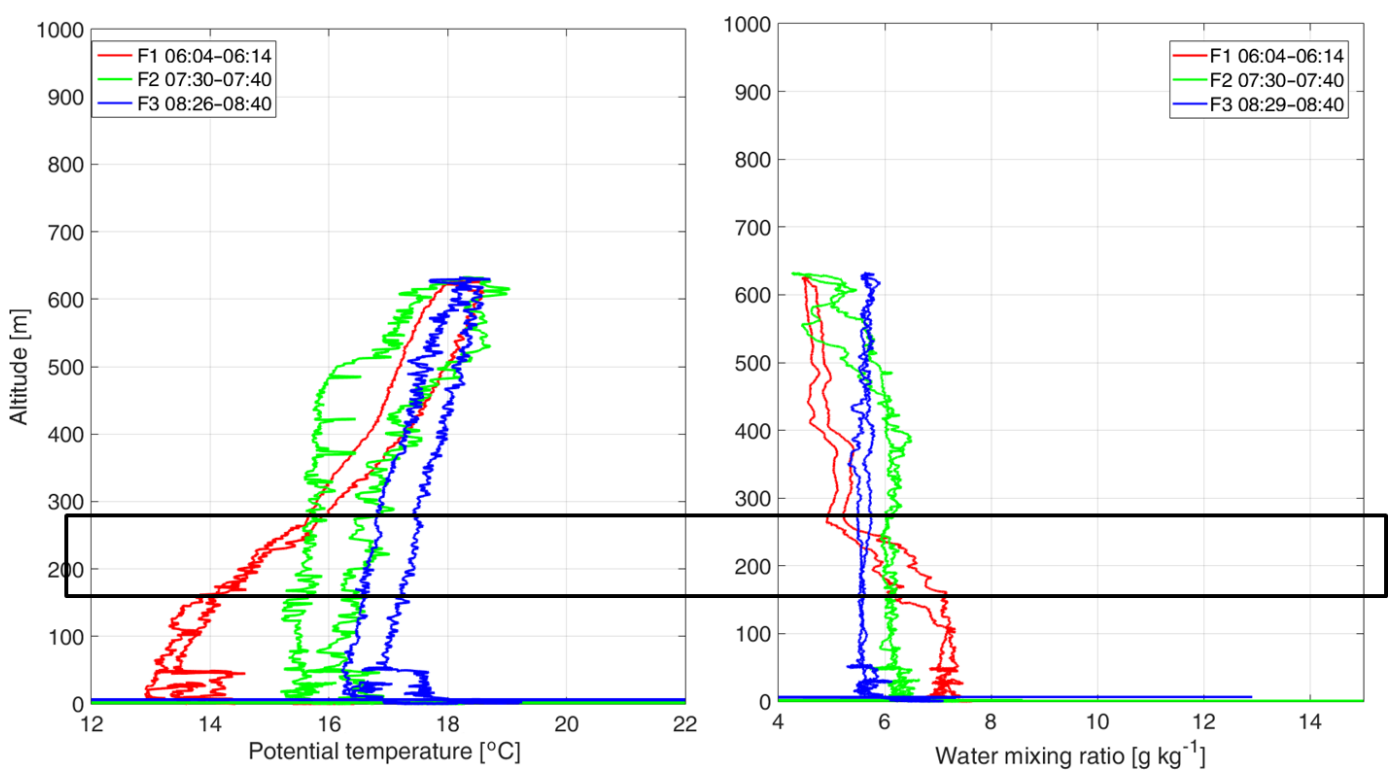

Figure 7. Profiles of potential temperature and water vapour mixing ratio obtained on 23 May 2018. The times of the five flights are given in UTC. The horizontal box represents the height interval of the temperature inversion, which is also visible in the large changes of the water vapour mixing ratio. 


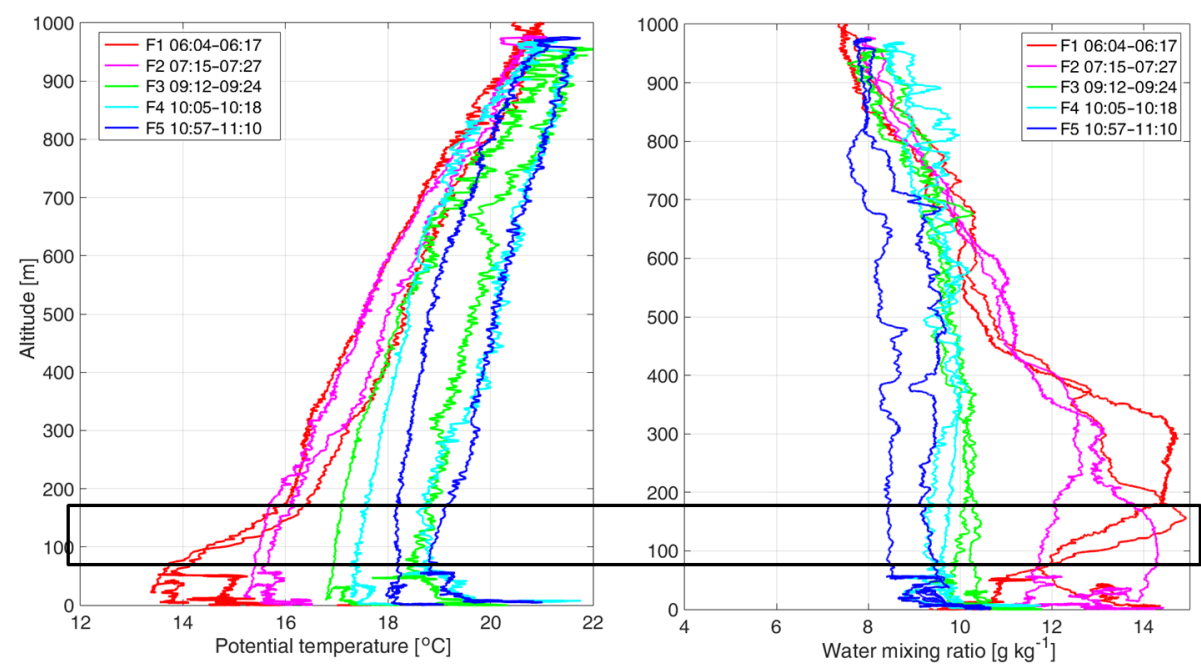

Figure 8. Profiles of potential temperature and water vapour mixing ratio obtained on 5 September 2018. The times of the three flights are given in UTC. The horizontal box represents the height interval of the temperature inversion, which is also visible in the large changes of the water vapour mixing ratio.
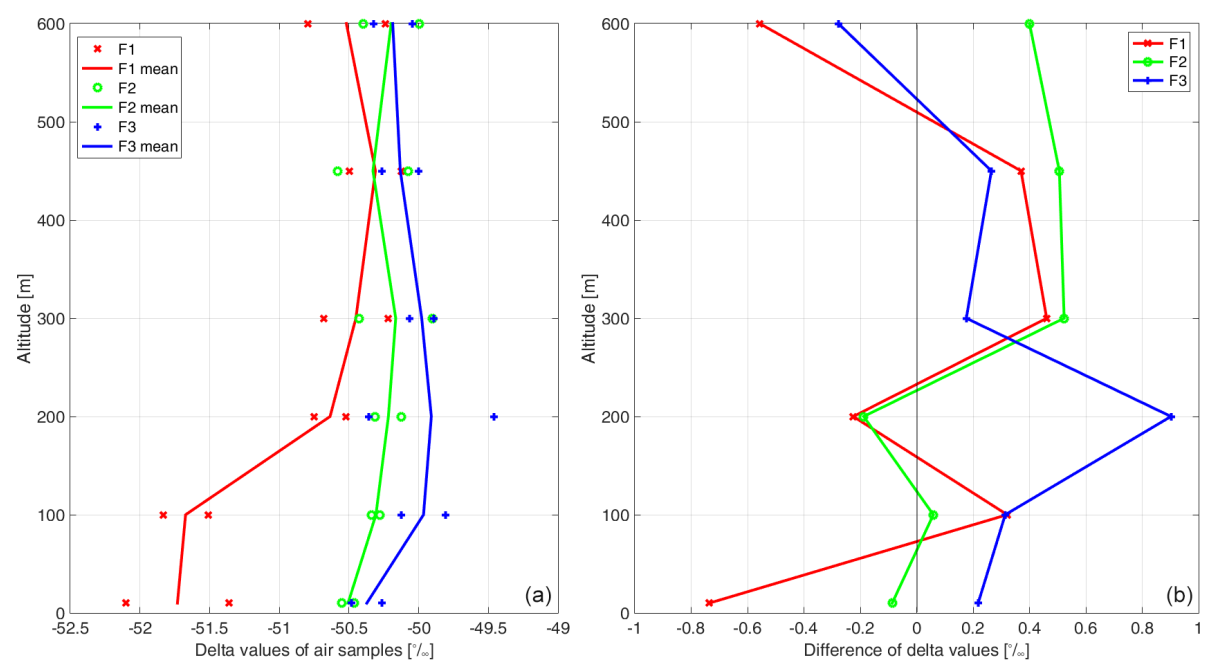

Figure 9. Profiles of (a) $\delta^{13} \mathrm{C}$ values for all air samples during the flights on 23 May 2018, and (b) difference of delta values between the double samples filled simultaneously at the same altitude.

et al., 2017). In the presented case, the parallel samples obtained at $10 \mathrm{~m}$ altitude seem to be mostly of the same spatial origin, with small differences in the delta value. Above, differences in the delta values are higher. A wind speed of less than $2 \mathrm{~m} \mathrm{~s}^{-1}$ during the sampling results in horizontal sample integration over not more than $4 \mathrm{~m}$ at the sampling altitude. Small-scale differences in methane isotopic composition can be introduced by intermittent vertical mixing processes, which may also be induced by the quadrocopter system itself. A high variability of methane sources is in agreement with the highly variable methane water concentrations measured within a radius of $100 \mathrm{~m}$ on 5 September 2018.

The difference in delta values obtained for air samples near the ground and above the temperature inversion during stable stratification is around $1.5 \%$, thus significantly higher than the uncertainties (flight 1 for each measurement day). This shows that the observed systematic vertical differences are not caused by measurement uncertainty but are due to local emissions in combination with limited mixing due to stable stratification. Other methane sources in the surroundings of the polder are presumably biological source processes as well; they may include larger areas of the rewetted peatland and ruminants, with similar isotopic composition (Röckmann et al., 2016).

Assuming that the parts of the surface with high methane concentrations, like samples Z-3, Z-4 and Z-6, act as a methane source, with a delta value of around -48 to $-49 \%$ (water sample Z-4 and Z-6), an isotopic fractiona- 

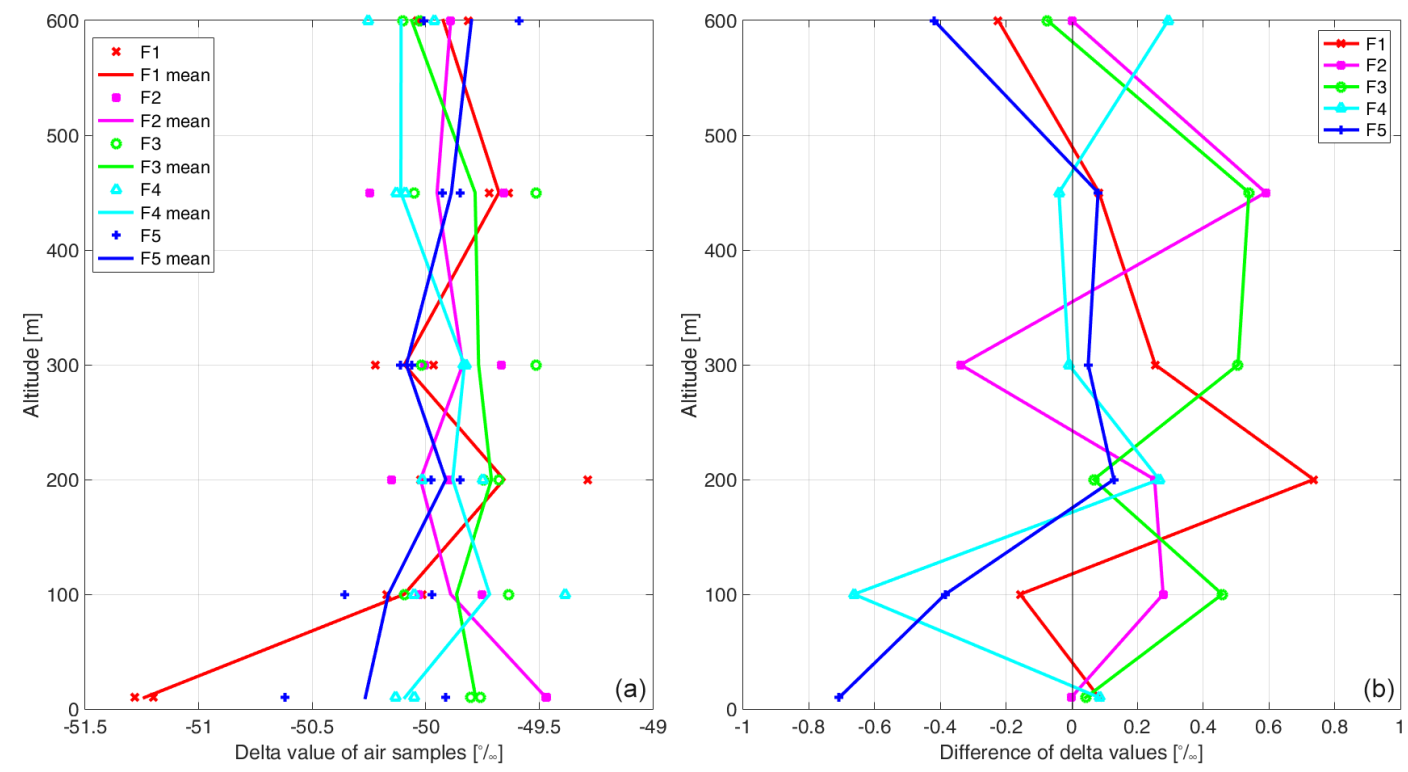

Figure 10. Profiles of (a) $\delta^{13} \mathrm{C}$ values for all air samples during the flights on 5 September 2018, and (b) difference of delta values between the double samples filled simultaneously at the same altitude.

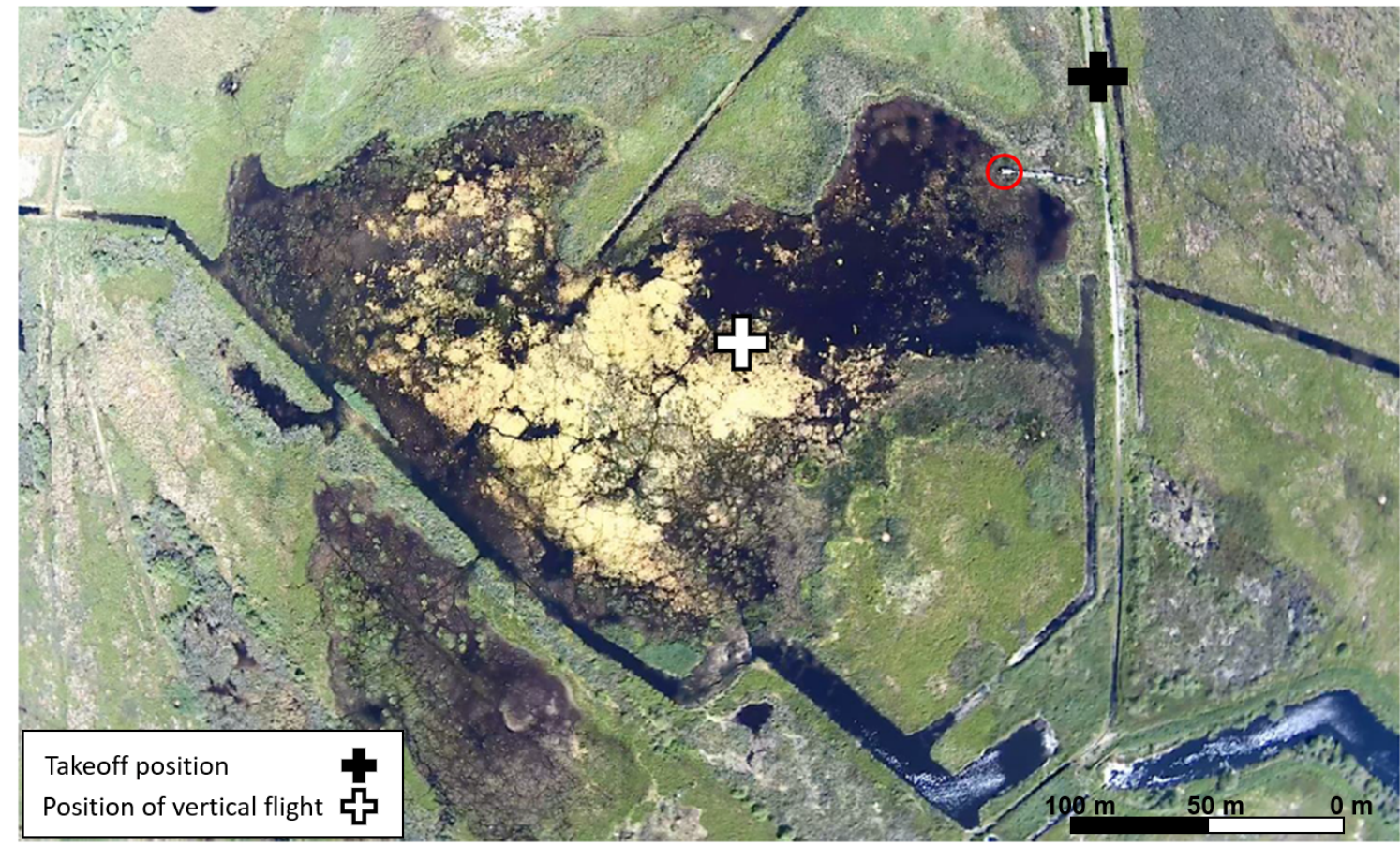

Figure 11. Aerial picture of Polder Zarnekow obtained with the quadrocopter ALICE on 23 May 2018. The location of the EC station is indicated with a red circle.

tion of around 3\%o would occur across the water-air boundary. This is in the order of magnitude of carbon isotope depletion observed for emitted relative to floodwater $\mathrm{CH}_{4}$, ranging from $1.8 \%$ to $3.4 \%$ (Happell et al., 1995) and thus can be considered realistic.

\subsection{Interpretation of isotopic composition from measurement point of view}

The isotopic composition of the two air samples taken on 5 September 2018 simultaneously but with a constant horizontal distance of $13 \mathrm{~cm}$ agree within $0.1 \%$ at the lowest 
altitude of $10 \mathrm{~m}$ for flights 1 to 4 (Fig. 10). This is a much better agreement than the uncertainty of $0.5 \%$. However, that latter value has been determined experimentally for long laboratory time series, while the uncertainty may be lower for subsequent analyses. Besides this strong locally and temporally related agreement of the isotopic composition, for other altitudes and flights this difference is in the range of the uncertainty. A possible explanation for the differences is a combination of spatial inhomogeneities and turbulent mixing processes.

The delta values are significantly more negative in the morning before vertical mixing starts, as long as a temperature inversion is present (first flight on 23 May 2018 below $150 \mathrm{~m}$, and first flight on 5 September 2018 below $70 \mathrm{~m}$ ). The difference between delta values below and above the temperature inversion is larger than the uncertainty. This is in agreement with methane from biologic processes emitted from the surface that is not mixed across the inversion.

Two aspects can be highlighted:

- The differences in delta values may indicate natural inhomogeneity. However, the very dynamic circulation process around the quadrocopter and the sampling time of $1.3 \mathrm{~s}$ have to be taken into account.

- Besides the vertical turbulent mixing, the natural spatial inhomogeneity of delta values is not known for the measurement site. Small-scale horizontal variability can be induced by inhomogeneous sources. Such variability of methane emissions at the field site as well as of the potential upwind $\mathrm{CH}_{4}$ sources may cause the inhomogeneous character of the air samples.

Altogether, a clear transition in the vertical distribution of the delta values can be seen.

\subsection{Improvement potential for multicopter based air sampling}

According to the simulations, undisturbed air sampling with the multicopter is possible with a sideways pointing inlet that reaches $25 \mathrm{~cm}$ beyond the rotor or a tube that reaches $50 \mathrm{~cm}$ above the rotors for hover and climb. Air sampling during descent experiences more additional disturbance by the rotor blades and therefore should be compared with air sampling during climb. The initial operation idea was to observe at first the atmospheric stratification in climb and determine the sampling altitudes for subsequent descent based on the altitude of the temperature inversion. However, the first simulation results quantify the difference in additional vertical velocities induced by the measurement system, which are much higher during descent (Fig. 3).

Due to efficiency reasons, the vertical climb speed is higher than the descent speed for the current ALICE system. The impact of the climb speed has to be taken into account for the temporal resolution of the sensors. In order to more closely constrain the altitude interval of the sampled air, measurements during hover or slow climb flight in combination with an inlet tube of the dimensions mentioned above would be preferable for continuous sampling. However, for the presented sampling system with small volume, the air volume contained in the tubes is not exchanged continuously and would further induce uncertainties.

Sampling during slow ascent or hover requires adjusting the battery capacities or the flight mission, e.g. the maximum flight altitude. Further, simulations of the whole multicopter system including the payload are required to quantify the flow field and find the optimal sensor location.

For a systematic comparison with the eddy flux measurements, temporally and spatially integrated measurements would be adequate. However, averaging is only suitable for sufficiently homogeneous surface conditions and emissions. This is not the case here, as already indicated by the different methane concentrations and isotopic compositions for the water samples. Therefore, the instantaneous point samples cannot be compared directly with the classical micrometeorological methods like $30 \mathrm{~min}$ averaged EC analyses. For further investigations of small-scale inhomogeneities, new methods for observations and analyses are required: simultaneous profiles of the methane concentration and isotopic composition upwind and downwind of an EC tower could be combined with wavelet analyses instead of EC covariance analyses, as suggested by Schaller et al. (2019).

\section{Conclusions}

The measurements serve both as a proof of concept for the system and show the vertical mixing of methane in the atmospheric boundary layer by means of its isotopic composition. With ALICE air samples and subsequent laboratory analyses, it is possible to determine vertical differences in the methane isotopic composition caused by atmospheric stability.

In summary, the first application of ALICE and the analyses of the air samples show potential for improvement for future missions:

- Air sampling during climb and hover is much less influenced by rotor-induced turbulence than during descent.

- Double sampling is highly recommended for system assessment.

- The punctual air sampling for delta value determination should be complemented with fast and accurate simultaneous onboard methane concentration measurements. Lightweight instruments with sufficient accuracy and temporal resolution might be operational in the near future.

The differences in delta values of water and air, the differences in delta values between both flight days, and the development during each day emphasize the highly complex 
and inhomogeneous nature of methane processes on horizontal scales below $1 \mathrm{~km}$ in sediments, at the sedimentwater and the water-atmosphere interfaces. Therefore, a suitable method is required for quantifying small-scale inhomogeneous methane sources. Vertical layering of air masses with different methane properties strongly depends on atmospheric stability, both concerning concentration as well as the isotopic composition. A holistic approach is needed to investigate methane processes from sediments to the atmospheric boundary layer, including dedicated measurements of the isotopic fractionation. Despite some points that can be improved, the first applications of ALICE for air sampling and methane isotopic analyses show the potential to contribute substantially to investigations of the layering and mixing processes of atmospheric methane of different sources. The use of the multicopter represents an advantage over air sampling at tall towers, as it is much more flexible and easier to apply.

Data availability. The data of the flight are available at PANGAEA (Pätzold et al., 2019) (https://doi.org/10.1594/PANGAEA.907759). Biometeorological and flux data will be uploaded to the European Fluxes Database Cluster (https://doi.org/10.18140/FLX/1440221, Sachs et al., 2020) after final processing and quality control.

Author contributions. AL wrote the paper. FP developed the quadrocopter payload. TK developed the quadrocopter. FP, TK, TR, $\mathrm{AL}$ and MA conducted the measurement campaigns. FP and ED performed the laboratory methane isotope analyses. CW and TS performed the methane flux measurements. LL performed the quality check of the copter measurements. DG, DSZ and SB performed the simulations. All authors contributed to and commented on the paper.

Competing interests. The authors declare that they have no conflict of interest.

Acknowledgements. The authors would like to thank Barbara Altstädter and two anonymous referees for critically reading the manuscript. Further, we would like to thank the associate editor Christof Ammann for his valuable comments.

Financial support. This research has been supported by the German Research Foundation (DFG) priority programme "Antarctic Research with comparative investigations in Arctic ice areas" (grant no. LA2907/8-1, DA1569/1-2).

This open-access publication was funded by Technische Universität Braunschweig.
Review statement. This paper was edited by Christof Ammann and reviewed by two anonymous referees.

\section{References}

Andersen, T., Scheeren, B., Peters, W., and Chen, H.: A UAV-based active AirCore system for measurements of greenhouse gases, Atmos. Meas. Tech., 11, 2683-2699, https://doi.org/10.5194/amt-11-2683-2018, 2018.

Andersson, A., Falck, E., Sjöblom, A., Kljun, N., Sahlée, E., Omar, A. M., and Rutgersson, A.: Air-sea gas transfer in high Arctic fjords, Geophys. Res. Lett., 2519-2526, https://doi.org/10.1002/2016GL072373, 2017.

Bärfuss, K., Pätzold, F., Altstädter, B., Kathe, E., Nowak, S., Bretschneider, L., Bestmann, U., and Lampert, A.: New Setup of the UAS ALADINA for Measuring Boundary Layer Properties, Atmospheric Particles and Solar Radiation, Atmosphere, 9, 28, https://doi.org/10.3390/atmos9010028, 2018.

Bellisario, L. M., Bubier, J. L., and Moore, T. R.: Controls on $\mathrm{CH}_{4}$ emissions from a northern peatland, Global Biogeochem. Cy., 13, 1, 81-91, 1999.

Brosy, C., Krampf, K., Zeeman, M., Wolf, B., Junkermann, W., Schäfer, K., Emeis, S., and Kunstmann, H.: Simultaneous multicopter-based air sampling and sensing of meteorological variables, Atmos. Meas. Tech., 10, 2773-2784, https://doi.org/10.5194/amt-10-2773-2017, 2017.

Chang, C.-C., Wang, J.-L., Chang, C.-Y., Liang, M.-C., and Lin, M.-R.: Development of a multicopter-carried whole air sampling apparatus and its applications in environmental studies, Chemosphere, 144, 484-492, 2016.

Chang, C.-C., Chang, C.-Y., Wang, J-L., Lin, M.-R., Ou-Yang, C.F., Pan, H.-H., and Chen, Y.-C.: A study of atmospheric mixing of trace gases by aerial sampling with a multi-rotor drone, Atmos. Environ., 184, 254-261, 2018.

Chen, J., Wilson, C., and Tapley, B.: The 2009 exceptional Amazon flood and interannual terrestrial water storage change observed by GRACE, Water Resour. Res., 46, W12526, https://doi.org/10.1029/2010WR009383, 2010.

Couwenberg, J., Thiele, A., Tanneberger, F., Augustin, J., Bärisch, S., Dubovik, D., Liashchynskaya, N., Michaelis, D., Minke, M., Skuratovich, A., and Joosten, H.: Assessing greenhouse gas emissions from peatlands using vegetation as a proxy, Hydrobiologia, 674, 67-89, 2011.

Damm, E., Rudels ,B., Schauer, U., Mau, S., and Dieckmann, G.: Methane excess in Arctic surface water - triggered by sea ice formation and melting, Sci. Rep.-UK, 5, 16179, https://doi.org/10.1038/srep16179, 2015.

Damm, E., Bauch, D., Krumpen, T., Rabe, B., Korhonen, M., Vinogradova, E. L., and Uhlig, C. : The Transpolar Drift conveys methane from the Siberian Shelf to the central Arctic Ocean, Sci. Rep.-UK, 8, 4515, https://doi.org/10.1038/s41598-018-22801-z, 2018.

Dlugokencky, E., Houweling, S., Bruhwiler, L., Masarie, K., Lang, P., Miller, J., and Tans, P.: Atmospheric methane levels off: Temporary pause or a new steady-state?, Geophys. Res. Lett., 30, 1992, https://doi.org/10.1029/2003GL018126, 2003.

Dlugokencky, E., Bruhwiler, L., White, J., Emmons, L., Novelli, P., Montzka, S., Masarie, K., Lang, P., Crotwell, A., Miller, J., 
and Gatti, L.: Observational constraints on recent increases in the atmospheric $\mathrm{CH}_{4}$ burden, Geophys. Res. Lett., 36, L18803, https://doi.org/10.1029/2009GL039780, 2009.

Dlugokencky, E., Crotwell, A., Masarie, K., White, J., Lang, P., and Crotwell M.: NOAA Measurements of Long-lived Greenhouse Gases, Asia-Pacific GAW Greenhouse Gases, 6, 6-9, 2013.

Emeis, S.: Examples for the determination of turbulent (subsynoptic) fluxes with inverse methods, Meteorol. Z., 17, 1, 003011, 2008

Etminan, M., Myhre, G., Highwood, E. J., and Shine, K. P.: Radiative forcing of carbon dioxide, methane, and nitrous oxide: A significant revision of the methane radiative forcing, Geophys. Res. Lett., 43, 12.614-12.623, https://doi.org/10.1002/2016GL071930, 2016.

Fenwick, L., Capelle, D., Damm, E., Zimmermann, S., William, J., Williams, W. J., Vagle, S., and Tortell, P. D.: Methane and nitrous oxide distributions across the North American Arctic Ocean during summer, 2015, J. Geophys. Res.-Oceans, 122, 390-412, https://doi.org/10.1002/2016JC012493, 2017.

France, J. L., Cain, M., Fisher, R. E., Lowry, D., Allen, G., O’Shea, D. J., Illingworth, S., Pyle, J., Warwick, N., Jones, B. T., Gallagher, M. W., Bower, K., Le Breton, M., Percival, C. Muller, J., Welpott, A., Bauguitte, S., George, C., Hayman, G. D., Manning, A. J., Lund Myhre, C., Lanoiselle, M., and Nisbet, E. G.: Measurements of $\delta^{13} \mathrm{C}$ in $\mathrm{CH}_{4}$ and using particle dispersion modelingg to characterize sources of Arctic methane within an air mass, J. Geophys. Res.-Atmos., 121, 14257-14270, 2016.

Franz, D., Koebsch, F., Larmanou, E., Augustin, J., and Sachs, T.: High net $\mathrm{CO}_{2}$ and $\mathrm{CH}_{4}$ release at a eutrophic shallow lake on a formerly drained fen, Biogeosciences, 13, 3051-3070, https://doi.org/10.5194/bg-13-3051-2016, 2016.

Gelbrecht, J., Zak, D., and Augustin, J. (eds.): Phosphorund Kohlenstoff-Dynamik und Vegetationsentwicklung in wiedervernässten Mooren des Peenetals in Mecklenburg-Vorpommern, Status, Steuergrößen und Handlungsmöglichkeiten, report 26/2008 of Leibniz-Institute of Freshwater Ecology and Inland Fisheries, Berlin, 101 pp., 2008.

Golston, L. M., Tao, L., Brosy, C., Schäfer, K., Wolf, B., McSpiritt, J., Buchholz, B., Caulton, D. R., Pan, D., Zondlo, A., Yoel, D., Kunstmann, H., and McGregor, M.: Lightweight mid-infrared methane sensor for unmanned aerial systems, Appl. Phys. BLasers O., 123, 1-9, https://doi.org/10.1007/s00340-017-6735-6, 2017.

Graf, M., Emmenegger, L., and Tuzson, B.: Compact, circular, and optically stable multipass cell for mobile laser absorption spectroscopy, Opt. Lett., 43, 2434-2437, 2018.

Gurlit, W., Zimmermann, R., Giesemann, C., Fernholz, T., Ebert, V., Wolfrum, J., Platt, U., and Burrows, J. P.: Lightweight diode laser spectrometer CHILD (Compact High-altitude In-situ Laser Diode) for balloonborne measurements of water vapor and methane, Appl. Opt., 44, 91-102, 2005.

Happell, J. D., Chanton, J. P., and Showers, W. J.: Methane transfer across the water-air interface in stagnant wooded swamps of Florida: Evaluation of mass-transfer coefficients and isotopic fractionation, Limnol. Oceanogr., 40, 290-298, 1995.

Heinrich, I., Balanzategui, D., Bens, O., Blasch, G., Blume, T., Böttcher, F., Borg, E., Brademann, B., Brauer, A., Conrad, C., Dietze, E., Dräger, N., Fiener, P., Gerke, H. H., Güntner, A., Heine, I., Helle, G., Herbrich, M., Harfenmeister, K., Heußner,
K., Hohmann, C., Itzerott, S., Jurasinski, G., Kaiser, K., Kappler, C., Koebsch, F., Liebner, S., Lischeid, G., Merz, B., Missling, K. D., Morgner, M., Pinkerneil, S., Plessen, B., Raab, T., Ruhtz, T., Sachs, T., Sommer, M., Spengler, D., Stender, V., Stüve, P., and Wilken, F.: Interdisciplinary Geo-ecological Research across Time Scales in the Northeast German Lowland Observatory (TERENO-NE), Vadose Zone J., 17, 1-25, 2018.

Hoffmann, M., Schulz-Hanke, M., Garcia Alba, J., Jurisch, N., Hagemann, U., Sachs, T., Sommer, M., and Augustin, J.: A simple calculation algorithm to separate highresolution $\mathrm{CH}_{4}$ flux measurements into ebullition- and diffusionderived components, Atmos. Meas. Tech., 10, 109-118, https://doi.org/10.5194/amt-10-109-2017, 2017.

Kirschke, S., Bousquet, P., Ciais, P., Saunois, M., Canadell, J. G., Dlugokencky, E. J., Bergamaschi, P., Bergmann, D., Blake, D. R., Bruhwiler, L., Cameron-Smith, P., Castaldi, S., Chevallier, F., Feng, L., Fraser, A., Heimann, M., Hodson, E. L., Houweling, S., Josse, B., Fraser, P. J., Krummel, P. B., Lamarque, J.-F., Langenfelds, R. L., Le Quere, C., Naik, V., O’Doherty, S., Palmer, P. I., Pison, I., Plummer, D., Poulter, B., Prinn, R. G., Rigby, M., Ringeval, B., Santini, M., Schmidt, M., Shindell, D. T., Simpson, I. J., Spahni, R., Steele, L. P., Strode, S. A., Sudo, K., Szopa, S., van der Werf, G. R., Voulgarakis, A., van Weele, M., Weiss, R. F., Williams, J. E., and Zeng, G.: Three decades of global methane sources and sinks, Nat. Geosci., 6, 813-823, 2013.

Kohnert, K., Juhls, B., Muster, S., Antonova, S., Serafimovich, A., Metzger, S., Hartmann, J., and Sachs, T.: Toward understanding the contribution of waterbodies to the methane emissions of a permafrost landscape on a regional scale - A case study from the Mackenzie Delta, Canada, Glob. Change Biol., 24, 39763989, 2018.

Mau, S., Blees, J., Helmke, E., Niemann, H., and Damm, E.: Vertical distribution of methane oxidation and methanotrophic response to elevated methane concentrations in stratified waters of the Arctic fjord Storfjorden (Svalbard, Norway), Biogeosciences, 10, 6267-6278, https://doi.org/10.5194/bg-10-6267-2013, 2013.

Mau, S., Römer, M., Torres, M. E., Bussmann, I., Pape, T., Damm, E., Geprägs, P., Wintersteller, P., Hsu, C.-W., Loher, M., and Bohrmann, G.: Widespread methane seepage along the continental margin off Svalbard - from Bjørnøya to Kongsfjorden, Sci. Rep.-UK, 7, 42997, https://doi.org/10.1038/srep42997, 2017.

Menter, F. R.: Two-equation eddy-viscosity turbulence models for engineering applications, AIAA J., 32, 1598-1605, 1994.

Miftah El Khair, Z., Joly, L., Cousin, J., Decarpenterie, T., Dumelié, N., Maamary, R., Chauvin, N., and Durry, G.: In situ measurements of methane in the troposphere and the stratosphere by the Ultra Light SpEctrometer Amulse, Appl. Phys. B, 123, 281, https://doi.org/10.1007/s00340-017-6850-4, 2017.

Nisbet, E. G., Dlugokencky, E. J., Manning, M. R., Lowry, D., Fisher, R. E., France, J. L., Michel, S. E., Miller, J. B., White, J. W. C., Vaughn, B., Bousquet, P., Pyle, J. A., Warwick, N. J., Cain, M., Browwnlow, R., Zazzeri, G., Lanoiselle, M., Manning, A. C., Gloor, E., Worthy, D. E. J., Brunke, E.-G., Labuschagne, C., Wolff, E. W., and Ganesan, A. L.: Rising atmospheric methane: 2007-2014 growth and isotopic shift, Global Biogeochem. Сy., 30, 1356-1370, 2016.

Pätzold, F., Krüger, T., Nowak, S., Damm, E., Bärfuss, K., Rausch, T., Asmussen, M., and Lampert, A.: Unmanned air sampling quadrocopter for studying boundary layer methane isotopy and 
vertical mixing processes - initial field test data, Zarnekow 2018, PANGAEA, https://doi.org/10.1594/PANGAEA.907759, 2019.

Platt, S. M., Eckhardt, S., Ferré, B., Fisher, R. E., Hermansen, O., Jansson, P., Lowry, D., Nisbet, E. G., Pisso, I., Schmidbauer, N., Silyakova, A., Stohl, A., Svendby, T. M., Vadakkepuliyambatta, S., Mienert, J., and Lund Myhre, C.: Methane at Svalbard and over the European Arctic Ocean, Atmos. Chem. Phys., 18, 17207-17224, https://doi.org/10.5194/acp-18-17207-2018, 2018.

Röckmann, T., Eyer, S., van der Veen, C., Popa, M. E., Tuzson, B., Monteil, G., Houweling, S., Harris, E., Brunner, D., Fischer, H., Zazzeri, G., Lowry, D., Nisbet, E. G., Brand, W. A., Necki, J. M., Emmenegger, L., and Mohn, J.: In situ observations of the isotopic composition of methane at the Cabauw tall tower site, Atmos. Chem. Phys., 16, 10469-10487, https://doi.org/10.5194/acp-16-10469-2016, 2016.

Sachs, T., Giebels, M., Boike, J., and Kutzbach, L.: Environmental controls of $\mathrm{CH}_{4}$ emission from polygonal tundra on the microsite scale, Lena River Delta, Siberia, Glob. Change Biol., 16, 3096-3110, 2010.

Sachs, T., Wille, C., Larmanou, E., and Franz, D.: (20132014) FLUXNET2015 DE-Zrk Zarnekow, Dataset, Fluxdata, https://doi.org/10.18140/FLX/1440221, 2020.

Sasaki, M., Kim, Y.-W., Uchida, M., and Utsumi, M.: Diffusive summer methane flux from lakes to the atmosphere in the Alaskan arctic zone, Polar Sci., 10, 303-311, 2016.

Schaller, C., Kittler, F., Foken, T., and Göckede, M.: Characterisation of short-term extreme methane fluxes related to nonturbulent mixing above an Arctic permafrost ecosystem, Atmos. Chem. Phys., 19, 4041-4059, https://doi.org/10.5194/acp19-4041-2019, 2019.

Shindell, D. T., Faluvegi, G., Bell, N., and Schmidt, G. A.: An emissions-based view of climate forcing by methane and tropospheric ozone, Geophys. Res. Lett., 32, L04803, https://doi.org/10.1029/2004GL021900, 2005.

Shindell, D. T., Faluvegi, G., Koch, D. M., Schmidt, G. A., Unger, N., and Bauer, S. E.: Improved attribution of climate forcing to emissions, Science, 326, 716-718, 2009.

Solomon, S., Qin, D., Manning, M., Chen, Z., Marquis, M., Averyt, K. B., Tignor, M., and, Miller, H. L. (eds.): Contribution of Working Group I to the Fourth Assessment Report of the Intergovernmental Panel on Climate Change, Cambridge University Press, Cambridge, UK and New York, NY, USA, 2007.

Sugawara, S., Nakazawa, T., Shirakawa, Y., Kawamura, K., and Aoki, S.: Vertical profile of the carbon isotopic ratio of stratospehric methane over Japan, Geophys. Res. Lett., 24, 2989 2992, 1997.
Uhlig, C. and Loose, B.: Using stable isotopes and gas concentrations for independent constraints on microbial methane oxidation at Arctic Ocean temperatures, Limnol. Oceanogr.-Meth., 15, 737-751, 2017.

Umezawa, T., Machida, T., Aoki, S., and Nakazawa, T.: Contributions of natural and anthropogenic sources to atmospheric methane variations over western Siberia estimated from its carbon and hydrogen isotopes, Global. Biogeochem. Cy., 26, GB4009, https://doi.org/10.1029/2011GB004232, 2012.

Verdugo, J., Damm, E., Snoeijsc, P., Diez, B., and Farias, L.: Climate relevant trace gases $\left(\mathrm{N}_{2} \mathrm{O}\right.$ and $\left.\mathrm{CH}_{4}\right)$ in the Eurasian Basin (Arctic Ocean), Deep-Sea Res. Pt. I, 117, 84-94, 2016.

Wolf, B., Chwala, C., Fersch, B., Garvelmann, J., Junkermann, W., Zeeman, M. J., Angerer, A., Adler, B., Beck, C., Brosy, C., Brugger, P., Emeis, S., Dannenmann, M., De Roo, F., Diaz-Pines, E., Haas, E., Hagen, M., Hajnsek, I., Jacobeit, J., Jagdhuber, T., Kalthoff, N., Kiese, R., Kunstmann, H., Kosak, O., Krieg, R., Malchow, C., Mauder, M., Merz, R., Notarnicola, C., Philipp, A., Reif, W., Reineke, S., Rödiger, T., Ruehr, N., Schäfer, K., Schrön, M., Senatore, A., Shupe, H., Völksch, I., Wanninger, C., Zacharias, S., and Schmid, H. P.: The SCALEX Campaign: Scale-Crossing Land Surface and Boundary Layer Processes in the TERENO-preAlpine Observatory, B. Am. Meteorol. Soc., 98, 1217-1234, 2017.

Wunch, D., Wennberg, P. O., Toon, G. C., Keppel-Aleks, G., and Yavin, Y. G.: Emissions of greenhouse gases from a North American megacity, Geophys. Res. Lett., 36, L15810, https://doi.org/10.1029/2009GL039825, 2009.

Yu, J., Xie, Z., Sun, L, Kang, H., He, P., and Xing, G.: $\delta^{13} \mathrm{C}-\mathrm{CH}_{4}$ reveals $\mathrm{CH}_{4}$ variations over oceans from mid-latitudes to the Arctic, Sci. Rep.-UK, 5, 13760, https://doi.org/10.1038/srep13760, 2015.

Zak, D., Reuter, H., Augustin, J., Shatwell, T., Barth, M., Gelbrecht, J., and McInnes, R. J.: Changes of the $\mathrm{CO}_{2}$ and $\mathrm{CH}_{4}$ production potential of rewetted fens in the perspective of temporal vegetation shifts, Biogeosciences, 12, 2455-2468, https://doi.org/10.5194/bg-12-2455-2015, 2015.

Zerbe, S., Steffenhagen, P., Parakenings, K., Timmermann, T., Frick, A., Gelbrecht, J., and Zak, D.: Ecosystem Service Restoration after 10 Years of Rewetting Peatlands in NE Germany, Environ. Manage., 51, 1194-1209, 2013. 